\title{
Construction of Wisdom Tourism and Tourism Public Service System
}

\author{
Xiaoru Gao \\ Sichuan Tianyi college, Chengdu, Sichuan, 610000
}

\begin{abstract}
Wisdom tourism is the inevitable choice to meet the special needs of tourists. So, how to promote the development of tourism public service system through the development of intelligent tourism? Existing research has neglected the construction of tourism public service system is affected by the interaction of multi-dimensional factors, and remain in the theoretical analysis stage, lack of empirical evidence. Therefore, based on the predecessors' research results, this paper uses the comprehensive evaluation method, spatial juice model and other empirical research methods to Jiangsu Province, the most mature intelligent tourism development for the research object, quantitative analysis of intelligent tourism development and tourism public service system construction The distribution pattern and its causes of the integrated level and the geographical space, the influence of the intelligent tourism development on the construction of the tourism public service system and the spatial difference.
\end{abstract}

Keywords: Wisdom Tourism, Tourism Public Service System

\section{Introduction}

"Wise tourism" is the development of computing technology in China to a certain extent, new products, there is no corresponding foreign vocabulary. At present, both the domestic information technology sector, or tourism academia and the industry, there is no more consistent definition. Most of the researches on intellectual tourism mainly focus on the analysis of the concept and connotation of "intelligent tourism". The deeper theoretical research on the public service 
system, supply relationship and public service system of intelligent tourism is little information at present. Checkable.

Wisdom tourism is a brand new term. According to the definition of "intelligent tourism", intelligent tourism refers to the use of cloud computing, Internet of things and other new technologies, through the Internet (or mobile Internet), with portable terminal equipment, Resources, tourism economy, tourism activities, tourists and other aspects of information and timely release, so that people can keep abreast of this information, the timely arrangements and adjustment of work and travel plans to achieve the various types of tourism information, intelligent perception, easy to use effect . "SmartToruism" by the Chinese scholars, the author through the "SmartToruism" retrieval of foreign literature, to find a foreign scholars on the "SmartToruism" understanding, he thinks SmartToruism ("SmartTourism"), Smart travel) is a means of providing travel information and travel-related services such as travel, food, transportation, reservations and travel guides to travelers conveniently through IT equipment. The definition of Wisdom Tourism in China is similar to that in Wisdom Tourism. Most of the researches focus on the analysis of the concept and connotation of Wisdom Tourism. Some scholars believe that Wisdom Tourism is a management change, While others think that is a new concept and new tourism development model, ... .... Which reflects the wisdom of tourism research is still in its infancy, most of the current research still remain in the surface. Although the term "tourism public service system" in China has appeared frequently in the tourism work reports of various departments in recent years, the existing research work mainly focuses on exploring the composition of tourism public services (system) from the perspective of functional components, However, there is still a lack of systematic study on the connotation, composition and operation of tourism public service, and the research on the public service of intelligent tourism is more rare.

\section{Development of Wisdom Tourism and Construction of Tourism Public Service System}

Technology support system, including cloud computing, Internet of things, mobile communications, large data, geographic information technology, is the intelligent tourism development and tourism public service system construction support and an important guarantee. The tourism public service system based on these nuclear tuition, ability, to provide comprehensive and efficient tourism information services, to promote the development of modern tourism service system, To assist law enforcement officers to improve law enforcement and management efficiency.

Service application system is mainly for tourists to provide intelligent tourism services, including tourism information services, tourism consulting services, hospitality services $\mathrm{H}$ content, is the wisdom of tourism development and tourism public service system construction system form. First of all, through the tourism information screen and interactive facilities for tourists to provide full media 
tourism information services. Government departments or tourism enterprises through public places to set up a tourist information screen and interactive television will be the local scenic spots, nearby hotels, restaurants, flight information, weather forecasts and other travel information through a wider range of richer media unified management, According to different places to set the content of the information screen to provide a friendly information screen control interface and additional features such as the bottom of the information screen set up into a tourist information frame, $\mathrm{W}$ ensure that tourists receive a full range of related travel information. Second, through the establishment of tourism advisory calls for tourists to provide full-channel travel advisory services. Government departments or tourism enterprises through public places, self-help touch screen, travel information, online customer service system, travel service 20 hotline, travel service providers official phone for tourists from different channels of the full range of travel advisory services, W better To meet the tourists before the tourism, tourism and tourism diversification of the demand, while promoting the development of tourism business.

The operation management system includes five parts: tourism e-government, travel safety rescue service, tour team service management, real-time blue-flow measurement and statistical analysis of tourist flow and tourist behavior management. It is a comprehensive system of intelligent tourism development and tourism public service system construction Improve business processes and improve the management level of the mechanism of protection. Tourism and tourism public service department to form tourism information sharing and collaboration linkage, tourism monitoring and forecasting mechanism to improve the emergency management capabilities to protect the safety of tourists to achieve the quality of tourism infrastructure, public complaints complaints and effective treatment.

The infrastructure system is the platform of the integrated system of the development of intelligent tourism and the construction of tourism public service system. Therefore, under the impetus of intelligent city and intelligent tourism, accelerate the construction of tourism public service system, improve and upgrade the infrastructure. And comprehensively promote the construction of infrastructure projects, including the construction of tourist destination port site, travel information technology projects, tourism, hotel information technology projects, construction of intelligent scenic spots, tourism and communication facilities.

\section{The System Construction of Intelligent Tourism Public Service}

The composition of tourism public service system is not a unified definition. In June 2012, the National Tourism Administration issued the Opinions on Further Doing a Good Job in Tourism Public Service. The Opinions put forward that by the end of 2015, the National Tourism Information and Consultation Service 
System, tourism security service system and convenient traffic service system will be perfected. , Tourism facilitation Huimin service system, tourism administrative service system, and other five systems. The author thinks that these five systems can be regarded as the most basic public service subsystem of the intelligent tourism public service system, and local public service subsystems can be added according to the local characteristics. Wisdom tourism public service system construction method of the core steps are as follows: First, determine the application layer subsystem functions. Tourism information service, travel security service, convenient traffic service, tourism convenience service and tourism administrative service as the basic five subsystems, according to their own characteristics of these five subsystems to supplement and simplify the functions. Secondly, for different objects, the public service supply demand analysis, the application layer is divided into the window layer and application support layer, the former directly to provide services for the object. Third, the application support layer security analysis, According to the security level of principle, it chooses the application layer support mode. Fourth, the establishment of tourism public service quality monitoring platform, including service quality standards organizations, third-party evaluation agencies and industry associations and such as monitoring bodies.

The best service is to create maximum value for all participants in the tourism activities. Wisdom tourism is not only a service platform, but also a resource sharing and value creation platform, through the platform of different subjects intertwined contact, build a tourism industry value network. Value network is a brand-new theoretical system based on customer-centric, complementary advantages of information technology and e-commerce infrastructure, and mutual cooperation of enterprises and institutions to create greater value of value creation system.

Value network theory is the expansion and upgrading of the value chain theory, it broke the traditional value chain model. Porter's value chain theory regards enterprise value activities as a linear chain. Enterprises and external relations are regarded as point-to-point links between two stakeholders. Value network combines suppliers, partners, customers and other interest groups Through the interaction between different levels linked into a number of interlocking value chain, so as to form a network in a number of aspects of the exchange relationship, so that information and knowledge can flow along multiple paths in the network, in this aggregation In the common to create more value. Value chain and the value chain is different: the value chain is concerned with supply and production links, the purpose is to reduce costs and enhance efficiency, while the value network is concerned about how to create greater value for customers and improve with the supplier's Value chain is concerned about the flow of production, while the value network is concerned about the value of the network of information flow through the sharing of knowledge for network members to create value, the value chain is only the supplier as the supply and demand of the trading relationship between the company and supply The value of the network as the value of the integrated network of partners, each member of the network to enhance its overall value has its contribution, and the value of superposition, so 
that the overall market boundaries The value chain to the customer as a marketing object, while the value of network put the customer as a business production and management of the participants, the consumer demand to become a part of production, and strengthen the communication with the customer is aimed at customers Value chain model is difficult to achieve low-cost and high-quality and derived from the value of the network through the excellent business process design so that each member in their own core competencies environment for lowcost operation, Therefore, in the value network model, enterprises can achieve product differentiation while leading the cost.

The traditional tourism industry value chain model is established under the condition that the information network is still relatively backward. In this value chain mode, the links among the members of the value chain are fixed, and the upper and lower members can not be flexible and multi- For example, the traditional travel industry chain, due to information asymmetry, members of the collaboration between the relatively poor, rigid value chain so that members of the group is only one member of the value chain, the value chain, Pay attention to the value and interests of their own enterprises, and easy to ignore the value and benefits of the entire value chain, combined with tourism consumers is difficult to fully understand the situation of tourism enterprises, tourism enterprises can not understand the needs of tourism consumers, resulting in tourism services to tourists Tourism value is difficult to fully realize.The tourism value network constructed on the basis of wisdom tourism is precisely based on the tourists as the core, the tourism resources as the foundation, the value increment and the creation as the Tourism enterprises and industry managers to establish information exchange network connection, tourists involved in the tourism production process to go and share the tourism production process, tourism enterprises to be fixed production, personalized custom, so that the Tourism industry is a cross-sectoral, cross-sectoral, cross-industry integrated industry, while the tourism industry has a simultaneous production and consumption of the same time, the tourism industry is a multi- The intelligent tourism system with the network structure will have the greatest flexibility and quickness, greatly enhance the depth and breadth of tourism services, thus greatly enhance the level of tourism public services.

\section{Conclusion}

This paper argues that the construction of tourism public service system is an important part of tourism system. Although it is based on a certain mode of supply, under the supervision of the government, the rational distribution of public service information for the majority of demand to provide efficient, scientific and reasonable tourism public services, but due to technology investment scale exponentially, Intelligent system and the diversification of the concept of tourism diversification and other factors, compared with the traditional tourism public service system, intelligent tourism public service system has its own characteristics, such as national security, supply mode selection principle, 
the supply of objects and Service diversity and so on. There is no doubt that these characteristics and scientific and technological ability and people's tourism concept is closely related to, and with their development and continuous improvement.

\section{References}

[1] Chen Jingxian, Xu Wendiao. Application of Internet of Things Technology in Wuyi Wisdom Tourism . Internet of Things, 2014

[2] Han Linghua, Yao Guozhang.Jiangsu Province wisdom tourism public service platform construction. Journal of Zhengzhou Institute of Aeronautical Industry Management, 3(1), pp. 101-104, 2003.

[3] Li Meng.Wisdom tourism based on the tourism public service mechanism innovation. Chinese Administration, 6(2), pp. 28-35, 2004.

[4] Ni Yn, Zhu Y. Research and application of intelligent tourism based on mobile Internet technology . Information Technology, 5(1), pp. 27-32, 2014.

[5] Li Yunpeng, Hu Zhongzhou, Huang Chao, Duan Liqiong.Discussion on the concept of intelligent tourism in the sight of tourist information service . Tourism Tribune, 5(1), pp. 20-25, 2014. 